\title{
Avaliação termográfica da cicatrização de feridas experimantais em ovinos
}

Fernanda Bovino; Matheus de Oliveira Souza Castro, Rafaela Speranza Baptista, Natalia Machado Rahal, Camila Sabino de Oliveira, Daniela Scantamburlo Denadai, Francisco Leydson Formiga Feitosa, Luiz Claudio Nogueira Mendes, Flavia de Almeida Lucas

Faculdade de Ciências Agrárias de Andradina (FCAA), Fundação Educacional de Andradina (FEA), Andradina, SP, Brasil

*Autor correspondente

e-mail: ferbovino@yahoo.com.br

Resumo

A termografia é usada para construir um mapa bidimensional da temperatura em toda a pele e como medida indireta do fluxo sanguíneo. Áreas com metabolismo mais elevado apresentam temperaturas mais altas do que áreas com menor atividade metabólica. As feridas de pele prejudicam o fluxo sanguíneo, alterando a perfusão tecidual e o fornecimento de oxigênio devido à ruptura de vasos, além de vasoconstricção periférica. 0 objetivo foi avaliar a temperatura cutânea em feridas experimentalmente induzidas nas regiões laterais do metacarpo e metatarso utilizando imagens termográficas. Foram utilizadas 12 ovelhas Suffolk, adultas e hígidas. Em seis delas, as feridas foram realizadas no lado direito e nas outras, no lado esquerdo dos metacarpos e metatarsos. Após sedação com cloridrato de xilazina a 2\% $(0,1 \mathrm{mg} / \mathrm{kg} \mathrm{IM})$ e bloqueio local infiltrativo com cloridrato de lidocaína a $2 \%$ sem vasoconstritor ao redor do local a ser excisado, as feridas foram confeccionadas com o auxílio de um molde quadrangular com $1 \mathrm{~cm}$ de lado, para a remoção do fragmento de pele. As feridas foram tratadas com solução fisiológica a 0,9\% e enfaixadas com atadura de crepe, em dias alternados, até completa cicatrização. As imagens foram realizadas antes $\left(D_{0 A}\right)$ e imediatamente após a ferida $\left(D_{0}\right)$, no terceiro $\left(D_{3}\right)$, no sétimo $\left(D_{7}\right)$ e no $15^{\circ}\left(D_{15}\right)$ dias pós-operatório. As imagens foram analisadas pelo programa Flir Tools ${ }^{\circledR}$ e os dados foram analisados por programa estatístico. Para determinar se houve diferenças significativas entre os momentos foi utilizado ANOVA seguido do teste de Tukey para as temperaturas do metacarpo e para as temperaturas do matatarso, em que não houve distribuição normal, utilizou-se o teste de Kruskal Wallis seguido do teste de Dunn. Para a comparação entre membros torácios e pélvicos em cada momento, foi utilizado o teste t pareado. 0 programa adotou o nível de significância de 5\%. Após 15 dias de observação, todas as feridas já haviam cicatrizado. Não houve diferença entre as temperaturas das feridas do metacarpo e do metatarso. Ao longo do tempo observou-se aumento da temperatura, com diferença significativa entre $D_{0 A}(30,4 \pm 2,0)$ e $D_{3}(32,3 \pm 1,7), D_{7}(33,1 \pm 1,6)$ e 
$\mathrm{D}_{15}(32,4 \pm 1,7)$ no metacarpo, e entre $\mathrm{D}_{0 \mathrm{~A}}(29,8 \pm 2,9)$ e $\mathrm{D}_{0}(31,4 \pm 1,9)$, diferente de $\mathrm{D}_{7}(33,9 \pm 1,3)$ e $\mathrm{D}_{15}(32,4 \pm$ 1,6) no metatarso. Entre três e sete dias após a lesão é esperado o pico da reação inflamatória, com formação de tecido de granulação e aumento da vascularização local, evidenciado no aumento da temperatura. Sendo assim, conclui-se que a termografia, um instrumento prático e não invasivo, fornecendo informações em tempo real das alterações circulatórias, pode ser utilizada na avaliação do processo cicatricial de feridas. 